\title{
Constitutive model equation for various types of rock specimen subjected to uniaxial compression loading
}

\author{
K Arora, T Chakraborty and KS Rao \\ Department of Civil Engineering \\ Indian institute of Technology Delhi \\ New Delhi, India \\ ketanarora24@gmail.com
}

\begin{abstract}
Right from the outset of the experimental determination of rock stress-strain response, researchers are performing uniaxial and tri-axial compression testing on the cylindrical specimens. In the last two-three decades' researchers have made an attempt to develop constitutive model considering anisotropy, rheological behavior and flaws in rock. In this project, static uniaxial compression tests are performed on cylindrical specimens of Kota sandstone, dolomitic limestone and three weathering classes of Delhi quartzite. Stress-strain curves have been plotted and a general constitutive model equation is derived for all the rock specimens. By observing stress-strain plot of different rock specimen, a parabolic relation between stress and strain is proposed containing two parameters $m$ and $n$. The fitted results by these models for all types of rock are compared with the experimental data and with the Hooke's law. It is concluded that the amended damage constitutive model can describe the stress- strain behavior of rock quite accurately.
\end{abstract}

Keywords - constitutive modelling; elastic modulus; hooke's law; uniaxial compressive strength; failure strain

\section{INTRODUCTION}

A rock is complex geological material having lot of complications in its study of engineering behavior. The principle of design in rock engineering are governed by it constitutive model $[1,2]$. Experimental study on rocks have revealed that stress-strain behavior of rock is non-linear and cannot be explained by Hooke's law. Attempts have been made in the past to develop constitutive model representing stress- strain relation of rocks under uniaxial and conventional tri-axial loading. Many researchers have developed a model keeping in mind the effect of on-linearity, anisotropy, rheology and other properties $[3,6]$.

Various models have been proposed such as hyperbolic model [7]; elastic perfectly plastic with Mohr-Coulomb friction; modified Ramberg-Osgood type model; directional dependent model and the HISS model [8] and [9]. A model based on polynomial expansion of yield function in terms of invariants of stress tensors is also proposed [10].

In this paper, constitutive model relation is proposed for a cylindrical rock specimen of $38 \mathrm{~mm}$ diameter and $76 \mathrm{~mm}$ length. Uniaxial compression experiments are conducted on
Kota sandstone, dolomitic limestone and three weathering classes of Delhi quartzite in stress control mode. A parabolic stress-strain relation is proposed by observing the stressstrain plots for all the experimental rock specimen. Finally, stress-strain equation parameters are derived for all the rock specimen and results are compared with the result by Hooke's law.

\section{UNIAXIAL LOADING TEST ON ROCKS}

\section{A. Testing Scheme}

Uniaxial compression tests are conducted on specimen of Kota sandstone, dolomitic limestone and three weathering classes of Delhi quartzite as per IS: 9143-1979 [11]. Kota sandstone was procured from Kota region in Rajasthan, Dolomitic limestone from Koldam, Himachal Pradesh and Delhi quartzite from Delhi metro tunneling site in Delhi. Rock specimens are prepared following the guidelines given in IS: 9179-1979[12] using a diamond edge cutting drill bit of $38 \mathrm{~mm}$ diameter and then finished to a cylindrical section of length to diameter ratio 2:1. All the experiments are conducted in Rock Mechanics Laboratory, IIT Delhi.

Uniaxial loading test is done in a stress control mode at a loading rate of $0.1 \mathrm{kN} / \mathrm{sec}$. Uniaxial compressive strength (UCS), $\sigma_{c}$ elastic Young's modulus, E of all the intact rock specimens of all the rock specimen. Five trials on each experiment are conducted and out of them best results have been presented herein. Since experiments are conducted in stress control mode, post failure stress-strain behavior of the rock specimen is not obtained.

\section{B. Experimental observations}

TABLE I indicates the physical and mechanical properties of all the rocks. Kota sandstone is having maximum UCS of 97.1 MPa and Elastic Young's modulus of $12.37 \mathrm{GPa}$. Intact sample of dolomitic limestone which is procured from Koldam Hydropower Project, Himachal Pradesh is having UCS of 78.2 MPa and Elastic Young's modulus of $11.84 \mathrm{GPa}$. Blocks of Delhi Quartzite were collected and are classified as Slightly Weathered (SW), Moderately Weathered (MW) and Highly Weathered (HW) [13]. SW Delhi quartzite specimen is very hard and stiff with UCS of $82.10 \mathrm{MPa}$ and Elastic Young's modulus of 48.4 GPa. MW Delhi Quartzite is found to have UCS of 41.77 
MPa and Elastic Young's Modulus of 13.51 GPa. HW Delhi Quartzite specimen is found to be very weak with UCS of $11.59 \mathrm{MPa}$ and Elastic Young's modulus of 1.26 GPa. Now, at stress equal to $50 \%$ of peak stress, slope of stress- strain curve gives elastic Young's modulus and mathematically it can be presented as,

TABle I. PhysicAl AND MeChanical Properties

\begin{tabular}{|l|l|l|l|l|l|}
\hline Property & \multirow{2}{*}{$\begin{array}{c}\text { Kota } \\
\text { sandstone }\end{array}$} & \multirow{2}{*}{$\begin{array}{c}\text { Dolomitic } \\
\text { limestone }\end{array}$} & \multicolumn{3}{|c|}{ Delhi quartzite } \\
\cline { 5 - 6 } & & & $\boldsymbol{S} \boldsymbol{W}$ & $\boldsymbol{M} \boldsymbol{W}$ & $\boldsymbol{H} \boldsymbol{H}$ \\
\hline$\rho\left(\mathrm{kg} / \mathrm{m}^{3}\right)$ & 2560 & 2699 & 2530 & 2430 & 2210 \\
\hline$G(\mathrm{GPa})$ & 2.71 & 2.87 & 2.64 & 2.65 & 2.67 \\
\hline$\sigma_{\mathrm{c}}(\mathrm{MPa})$ & 97.10 & 78.20 & 82.10 & 41.77 & 11.59 \\
\hline$E_{t}(\mathrm{GPa})$ & 12.37 & 11.84 & 48.40 & 13.51 & 1.26 \\
\hline
\end{tabular}

\section{CONSTITUtive RELATION}

The constitutive model of a rock is the mathematical relationship between the applied stress and correspondingly developed strain. Generally, behavior of a rock is studied in phase namely, pre-peak phase (before failure of specimen) and post-peak (after failure of specimen). Here constitutive relationship for pre-peak phase has been developed. Like any other mathematical function, constitutive relation is a mathematical formulation defining relationship between stress $(\sigma)$ and strain $(\varepsilon)$. One such widely known relation between stress $(\sigma)$ and strain $(\varepsilon)$ is Hooke's law for the materials which shows linear stress-strain relationship,

$$
O=E_{t} \varepsilon
$$

where, Et is the tangential elastic Young's modulus at a stress equivalent to $50 \%$ of the mean stress. However, stressstrain behavior of a material such as rock in most of the cases cannot be explained by Hooke's law. It is observed from Fig. 1 that material exhibit non-linear stress-strain relation and same has been depicted by many researchers.

Here, attempt is made to explain and develop a constitutive relation for non-linear stress-strain behavior of rock. It is observed from the stress-strain plot that a parabolic relation can used defined stress-strain relation which constitutes of two parameters $\mathrm{m}$ and $\mathrm{n}$. The relationship can be presented as,

$$
\sigma=E_{t}(m+n \varepsilon) \varepsilon
$$

where, Et is the elastic tangential modulus at $50 \%$ of peak stress or simply Young's modulus for the material. Constants $\mathrm{m}$ and $\mathrm{n}$ are the intact rock parameters and depends on the type of rock specimen. Parameters $m$ and $n$ can be obtained by experimental data using least square of regression.

If properties of intact rock specimen such as Young's modulus (Et), UCS $(\sigma c)$, failure strain $(\varepsilon f)$ and strain at 50\% of peak stress $(\varepsilon 50)$ are known, then $\mathrm{m}$ and $\mathrm{n}$ can be obtained by solving two equations with two linear variables. First equation can be obtained by substituting $\sigma$ as $\sigma_{c}$ and $\varepsilon$ as $\varepsilon f$ in (2) as,

$$
\sigma_{c}=E_{t}\left(m+n \varepsilon_{f}\right) \varepsilon_{f}
$$

To get second equation first differentiate (2) with respect to strain $(\varepsilon)$,

$$
\delta \sigma=\mathrm{E}(\mathrm{m}+2 \mathrm{n} \varepsilon)
$$

Now, at stress equal to $50 \%$ of peak stress, slope of stressstrain curve gives elastic Young's modulus and mathematically it can be presented as,

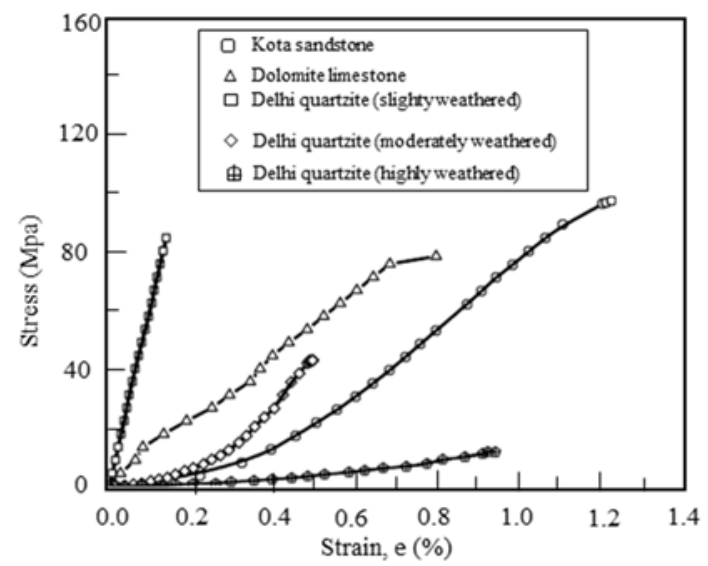

Fig. 1. Experimental stress-strain plot

\section{VERIFICATION AND DISCUSSION}

\section{A. Verification of the proposed model}

Uniaxial loading curves for Kota sandstone, dolomitic limestone and three weathering class of Delhi quartzite are fitted by using constitutive relation (2). The constants, $\mathrm{m}$ and $\mathrm{n}$, are obtained by least square of regression for all five rock specimens. The values of $m$ and $n$ obtained for all types of rock specimen tested here is presented in TABLE II along with the coefficient of determination obtained by fitting (1) in the stress strain relation.

TABLE II. R² VALUES COMPARISON

\begin{tabular}{|l|l|l|}
\hline \multirow{2}{*}{ Rock specimen } & \multicolumn{2}{|c|}{$R^{\mathbf{2}}$} \\
\cline { 2 - 3 } & Hooke's law & Proposed model \\
\hline Kota Sandstone & -0.78 & 0.95 \\
\hline Dolomitic limestone & 0.95 & 0.98 \\
\hline Slightly weathered Delhi Quartzite & 0.86 & 0.99 \\
\hline Moderately weathered Delhi Quartzite & -0.72 & 0.99 \\
\hline Highly weathered Delhi Quartzite & 0.75 & 0.99 \\
\hline
\end{tabular}

As can been observed from Fig. 2 (a), Hooke's law equation doesn't fit well and negative value of $\mathrm{R}^{2}$, as in TABLE III, is obtained which indicates very poor correlation. Proposed constitutive equation is found to fit well with the experimental data with value of $m$ and $n$ as53.73 and 0.06 respectively for Kota sandstone specimen respectively with $\mathrm{R}^{2}$ value of 0.95 . Dolomitic limestone experimental data are explained quite effectively by both Hooke's law equation with high $\mathrm{R}^{2}$ value of 0.95 . By 
applying proposed constitutive relation with parameters $\mathrm{m}$ and $n$ as -46.15 and 1.16 respectively we get $R^{2}$ value of 0.98 , as given in the Table III. Constitutive relation fitting

(a)

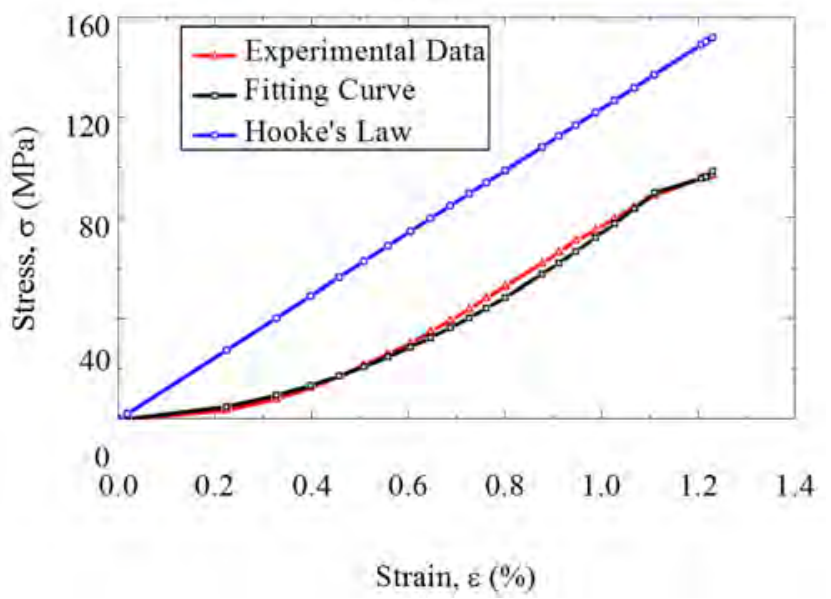

Fig. 2(a). Stress-strain fitting plot for Kota sandstone

(b)

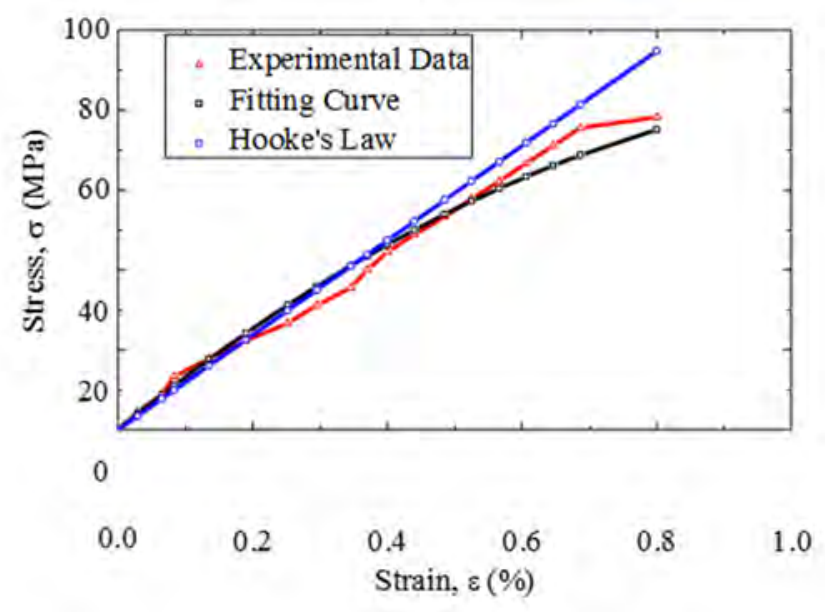

Fig. 2(b). Stress-strain fitting plot for dolomitic limestone

(c)

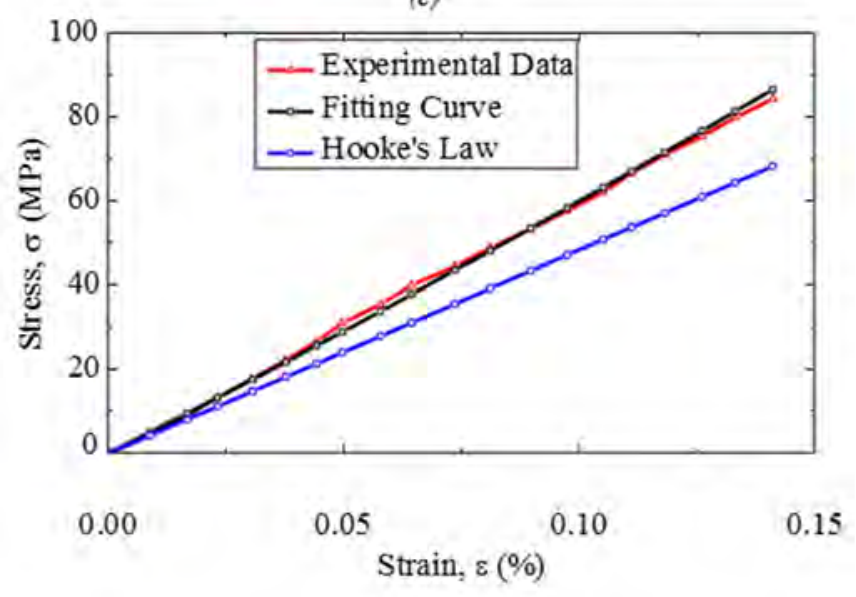

Fig. 2(c). Stress-strain fitting plot for slightly weathered Delhi quartzite along with Hooke's law fitting and experimental stressstrain curve is presented in Fig. 2 (b).

(d)

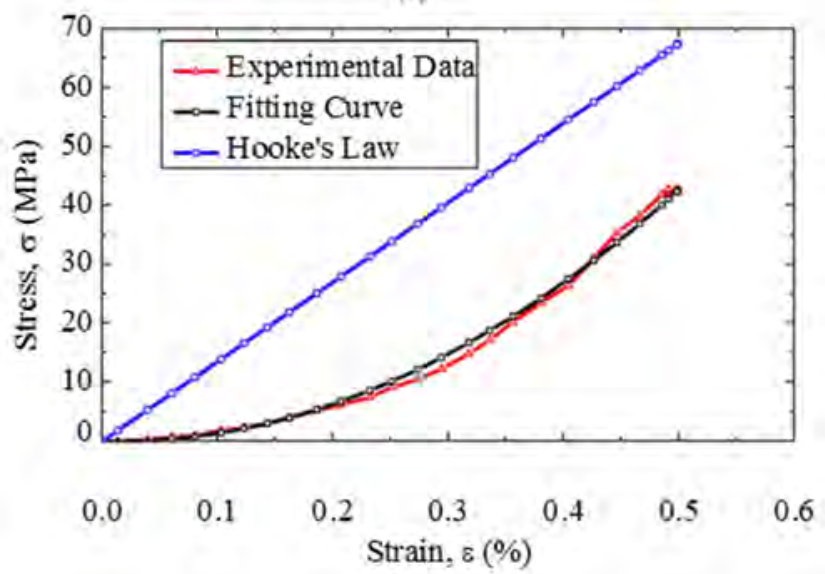

Fig. 2(d). Stress-strain fitting plot for moderately weathered Delhi quartzite

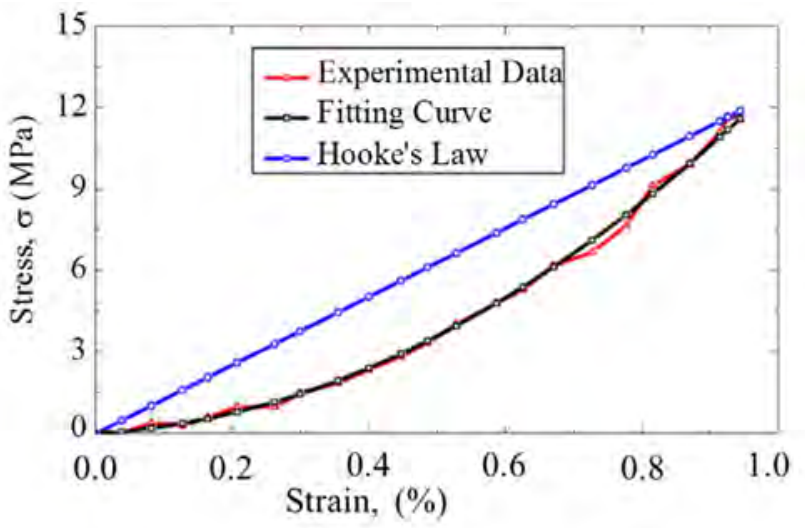

Fig. 2(e). Stress-strain fitting plot for highly weathered Delhi quartzite

Stress-strain behavior of slightly weathered Delhi quartzite limestone can be explained similar to behavior of dolomitic with $\mathrm{R}^{2}$ of 0.86 by fitting Hooke's law equation. Parameters $\mathrm{m}$ and $\mathrm{n}$ obtained by least square of regression are 69.53 and 1.17 respectively, with $\mathrm{R}^{2}$ value of 0.99 . Stress-strain plot by experimental data, Hooke's law and proposed constitutive relation are presented in Fig. 2(c).

Moderately weathered Delhi quartzite stress-strain behavior is found to be similar to that of Kota sandstone. R2 value of 0.72 obtained by Hooke's law, which indicated very poor fitting. Proposed constitutive equation is found to align well with experimental with value of parameters $m$ and $n$ as 133.22 and-0.03 respectively, with R2valueof0.99. Respective stress-strain plot is presented in Fig. 2(d).

Similar to dolomitic limestone and slightly weathered Delhi quartzite, stress-strain behavior of highly weathered quartzite can be predicted by Hooke's law but with less accuracy and R2 value of 0.75 . Proposed constitutive model fits well with experimental data as shown in Fig. 2(e) for this rock specimen with main $d n$ value as 91.45 and 0.113 respectively with value of R2 equal to 0.99 . 
The comparison of values of $\mathrm{R}^{2}$ by Hooke's law and proposed criteria are given in TABLE III. It can be observed from the results that the proposed model gives very high value of $\mathrm{R}^{2}$ in all the cases. Whereas, only brittle rock like dolomitic limestone and slightly weathered Delhi quartzite give acceptable value of $\mathrm{R}^{2}$ with Hooke's law.
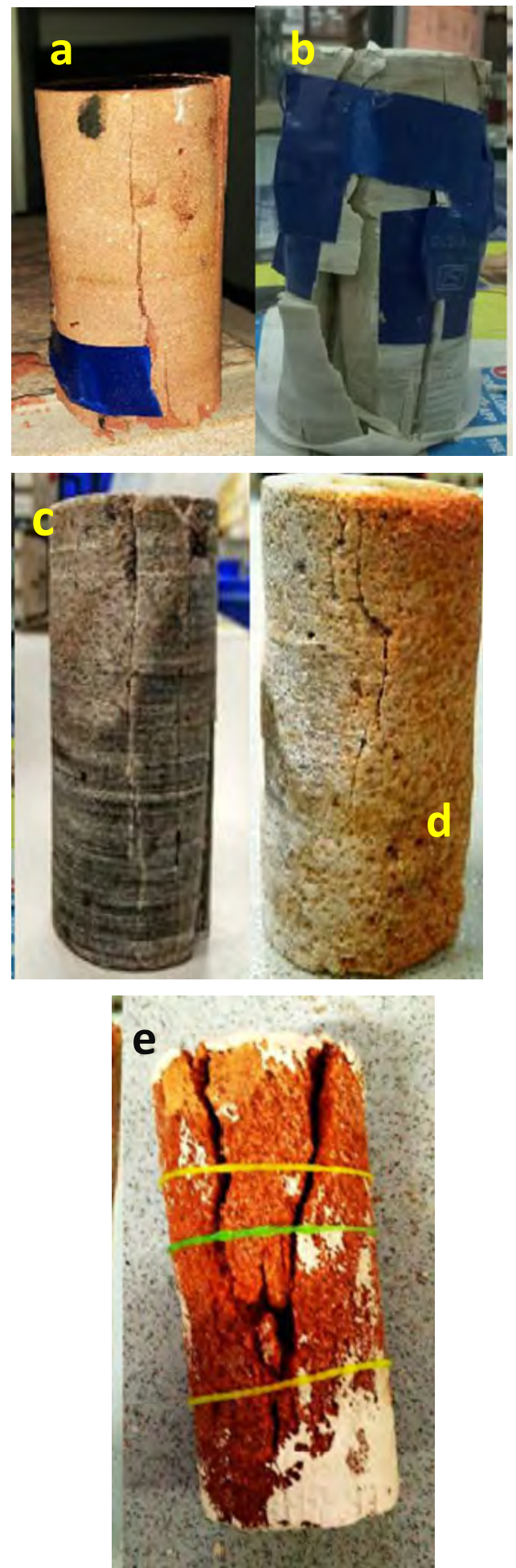

Fig. 3. Failure pattern (a) Kota sandstone, (b) dolomitic limestone, (c) slightly weathered Delhi quartzite, (d) moderately weathered Delhi quartzite and (e) highly weathered Delhi quartzite
TABLE III. ROCK SPECIMEN PARAMETERS

\begin{tabular}{|c|c|c|}
\hline \multirow[t]{2}{*}{ Rock specimen } & \multicolumn{2}{|c|}{ Proposed criteria parameters } \\
\hline & $m$ & $n$ \\
\hline Kota Sandstone & 53.73 & 0.06 \\
\hline Dolomitic limestone & -46.15 & 1.16 \\
\hline $\begin{array}{|lcc|}\begin{array}{l}\text { Slightly } \\
\text { Quartzite }\end{array} & \text { weathered } & \text { Delhi } \\
\end{array}$ & i 69.53 & 1.17 \\
\hline $\begin{array}{l}\begin{array}{l}\text { Moderately weathered Delhi } \\
\text { Quartzite }\end{array} \\
\end{array}$ & 133.22 & -0.03 \\
\hline $\begin{array}{|lll|}\begin{array}{l}\text { Highly } \\
\text { Quartzite }\end{array} & \text { weathered } & \text { Delhi } \\
\end{array}$ & 91.45 & 0.113 \\
\hline
\end{tabular}

Hence, Hooke's law doesn't fits well for this type of rock and stress-strain behavior can be explained by (2) with very high accuracy. Moderately weathered Delhi Quartzite despite of being a metamorphic rock show behavior similar to Kota sandstone because of the weathering of the material.

Stress-strain behavior of brittle rock such as dolomitic limestone and slightly weathered Delhi quartzite can be explained by Hooke' law as there is no pore closure before the failure. The proposed constitutive model relationship explains stress-strain behavior of these rock specimens with very high accuracy. Highly weathered Delhi quartzite is very soft rock with very low UCS and Et. The stress-strain behavior of this rock specimen is well explained well by proposed constitutive relation. Fig. 3 shows the failure pattern of all the rock specimen.

\section{CONCLUSIONS}

The aim of this work is to provide a strong correlation between axially applied stress and axial strain developed, by building a common constitutive model for different rock specimen. By comparing with the generally used Hooke's law for stress-strain relation, the work has original and widely applicable aspects.

By carefully observing the stress-strain plots of all the rock specimen tested here, it is clear that the behavior of all types of rock specimen cannot be explained by Hooke's law. Only brittle rock such as dolomitic limestone and slightly weathered Delhi quartzite are found to have acceptable results with Hooke's law.

\section{A. Discussions}

Kota sandstone is a sedimentary rock and has some pores which requires some seating loads for the closure. This is the reason for the convex shape of experimental stress-strain plot.

The proposed constitutive relation here captures the nonlinear behavior of the material with very high amount of accuracy. The model works well for hard rock such as slightly weathered Delhi quartzite to very soft rock such highly weathered Delhi quartzite and for sedimentary rock like Kota sandstone as well.

\section{REFERENCES}

[1] Pour hosseini, Omid, and M. Shabanimashcool, "Development of an elasto-plastic constitutive model for intactrocks." International Journalof Rock Mechanics and Mining Sciences 66, 2014, pp.1-12.

[2] G. M. Filz, J. A. Sloan, and J. G. Collin, "Field-scale column- 
supported embankment test facility", 2013, pp. 1- 12.

[3] J. Duriez, F. Darve, and F. V. Donze, "A discrete modeling-based constitutive relation for infilled rock joints", International Journal of Rock Mechanics and Mining Sciences 48.3, 2011, pp. 458-468.

[4] E. E. Alonso, M. T. Zandarín, and S. Olivella, "Joints in unsaturated rocks: thermo-hydro-mechanical formulation and constitutive behavior", Journal of Rock Mechanics and Geotechnical Engineering 5.3, 2013, pp.200-213.

[5] Deng, Jian, and G. Desheng, "On a statistical damage constitutive model for rock materials", Computers \& Geosciences 37.2, 2011, pp. 122-128.

[6] H. Y. Liu, S. R. Lv, L. M. Zhang, and X. P. Yuan, "A dynamic damage constitutive model for a rock mass with persistent joints." International Journal of Rock Mechanics and Mining Sciences 75, 2015, pp.132-139.

[7] Clough, G. Wayne, and J. M. Duncan, "Finite element analysis of retaining wall behavior", Journal of Soil Mechanics \& Foundations Div 99.sm 4, 1973.

[8] C. S. Desai, and K. L. Fishman, "Plasticity-based constitutive model with associated testing for joints", International Journal of Rock Mechanics and Mining Sciences \&Geomechanics Abstracts. Vol. 28.No.1. Pergamon, 1991

[9] C. S. Desai, and M. Youzhi, "Modelling of joints and interfaces using the disturbed-state concept", International Journal for Numerical and Analytical Methods in Geomechanics 16.9, 1992, pp. 623-653.

[10] C. S. Desai, and M. O. Faruque, "Constitutive model for (geological) materials", Journal of Engineering Mechanics 110.9, 1984, pp. 1391-1408.

[11] IS: 9143-1979, "Method for the determination of unconfined compressive strength of rock materials" Bureau of Indian Standards, New Delhi, 1979.

[12] IS: 9179-1979, "Method for the preparation of rockspecimen for laboratory testing”, Bureau of Indian Standards, New Delhi, 1979.

[13] A. S. Gupta, and K. S. Rao, "Weathering indices and their applicability for crystalline rocks" Bulletin of Engineering Geology and the Environment, 60(3), 2001, pp. 201-221. 